\title{
An Introduction to the Police Procedural: A Subgenre of the Detective Genre*
}

\author{
Fitria Akhmerti Primasita'; Heddy Shri Ahimsa-Putra² \\ ${ }^{1}$ English Department, Sebelas Maret University Surakarta, Indonesia; \\ ${ }^{2}$ Department of Anthropology, Universitas Gadjah Mada, Indonesia \\ Corresponding Email: fiakhta@yahoo.com
}

\begin{abstract}
Based on library research and observation, this paper aims to introduce the police procedural as a subgenre of the detective genre. To achieve this aim, this paper elaborates three definitions of police procedural. The discussion shows that experts have apparently provided a working definition of the police procedural after having identified how the new variant is different from, and yet remains the same as the "parent" genre. While the third definition puts emphasis on the authentic and realistic aspects of the police procedural, the first two definitions can be used as a reference to elaborately discuss the police procedural as a variant or subgenre of the detective genre. The police procedural retains the basic conventional elements of the detective genre-plot and motifs, character, setting, theme, and props, but it twists these elements and turns them into an invention with the intention of keeping the interest of the readers and viewers. Having established itself as a subgenre, the police procedural has grown to become formulaic by creating its own conventions. It is a formula that is generally employed by writers and has come to be expected by readers or viewers. By doing so, the police procedural has helped the detective genre as its "parents" genre stay popular.
\end{abstract}

Keywords: detective genre; police procedural subgenre; convention; invention

\section{INTRODUCTION}

The detective genre is among the most enduring genres of the American entertainment industry. Since the midnineteenth century (Bertens \& D'haen, 2001, p. 1; Horsley, 2005, p. 3; Bell, 2003, p. 8) to the present, the detective genre has flourished, not only in print, but also on radio and then on screen in both cinema and television. It has

*) This paper was written and developed based on the first author's dissertation in the American Studies Doctorate Program of the Faculty of Cultural Sciences, Gadjah Mada University, Yogyakarta, Central Java, Indonesia.

1) The first author is a doctorate candidate in American Studies of the American Studies Doctorate Program of the Faculty of Cultural Sciences, Gadjah Mada University, Yogyakarta, Central Java, Indonesia.

2) The second author is the promoter of the first author. undergone generic changes that are integrally related to shifting socio-political circumstances and to the dominant anxieties and preoccupations of different periods (Mittell, 2004, p. 30).

To become so powerful, the detective genre cannot merely rely on its textual conventions. In fact, it is the ability of the detective genre to transform itself to suit the taste of different generations of readers and viewers with new kinds of detectives, new techniques of detection, and even new types of crime, settings, and atmosphere that has caused the detective genre to endure (Dove, 1985 , p. 1). What has vitalized the detective genre is its ability to transform the existing pattern sufficiently enough to produce what then becomes to be classified as a new subgenre and even to challenge the readers and viewers' expectations by combining the elements of 
different genres and subgenres (Horsley, 2005, p. 5). As rightly summarized by R. Browne, the detective genre has become a powerful genre because it "develops through the conventional by use of the inventional, then folds back upon itself and consciously reuses the formulas and conventions to create a new power of convention and formula" (as cited in Horsley, 2005, p. 5).

Initially emerging in the late 1940s and early 1950 s, the police procedural subgenre can be seen as the detective genre's attempt to revitalize itself in the midst of the shifting socio-political conditions and the changing socio-cultural conditions of post-Second World War and post-Vietman War America (Panek, 2003, p. 155). The increasingly complex and organized nature of contemporary American society has resulted in the proliferation of new types of crime which require the right persons with authority to handle them - the police (Bertens \& D'haen, 2001, p. 3; Priestman, 2003, p. 5; Panek, 2003, p. 155; Dove, 1982, p. 10). In response to the new conditions, the detective genre saw the need to transform itself by representing real cops and the fascinating, tedious, traumatic, and thankless job they do and the ways in which their employment makes an impact on them (Panek, 2003, p. 155). This makes the police procedural the only variant of the detective genre that has counterparts in real life, and thus this variant relies more on realistic and authentic representation of the police and their work as well as their life (Dove, 1982, p. 3; Roman, 2005, p. 41; Mittell, 2004, p. 126).

Thus, the subgeneric label "police procedural" suggests not only different kind of detective, but also the technique of detection that is distinct from that of the detectives of past traditions. Unlike the "Great Detective" of the classical period and the "hard-boiled" private investigator, according to Gates (2006), the detective of the police procedural is a policeman/policewoman who relies more on the departmental procedures of the police force and his/her own resources of experience from years of dedication on the force. The police detective works professionally in a team and makes use of investigative technology a lot (p. 90).

It is then interesting to investigate further how the police procedural subgenre has helped its "parent" genre - the detective genre-maintain its popularity in the American entertainment industry. Therefore, applying library studies and observation, this paper aims to introduce the police procedural as a subgenre of the detective genre. To achieve this aim, this paper discusses three definitions of the police procedural to explore how the police procedural as a new variant of the detective genre is different from, and yet remains the same as the "parent" genre. Then, it further discusses the inventions of the new variant to know how it developed to become an established subgenre.

\section{DISCUSSION}

Critics have attempted to provide a direct, clear definition of their exploration of the police procedural as a new variant of the detective genre. The most logical explanation of this attempt is the police procedural is seen as the detective genre's effort to rejuvenate itself. The police procedural is produced through the ability of the detective genre to sufficiently transform its basic formal attributes and patterns of meaning. It is deemed necessary to identify the interplay between the familiar and twists of the familiar - how the new variant is different from, and yet the same as the "parent" genre- to eventually come up with a working definition of the new variant.

In his book The Police Procedural that is dedicated to thoroughly discussing the subgenre, G.N. Dove (1982) provided the easiest way to define the police procedural. He referred to the iconic American television cop drama Dragnet (NBC, 1951-59). According to Dove (1982), the police procedural is "the Dragnet kind of story, in which a mystery is solved by police detectives like Joe Friday and Frank Smith [the main-character detectives of Dragnet]" (p. 2). Harriss (2008) provided another definition. In his opinion, "[p]rocedurals filter the ratiocinative action through characters who actively investigate the mystery for the viewer, following procedures that are prescribed by their professions (e.g. police detectives, forensic scientists, etc.)" (p. 43).

Comparing the two definitions, it can be inferred that the police procedural is indeed a variant or subgenre of the detective genre. The two definitions suggest that there are at least two elements of the textual convention of the detective genre altered to create the subgenre- $-\mathrm{a}$ new type of detective and a new technique of detection. The elements of the textual convention of the detective genre include plot, motifs, character, setting, theme, and props (Nachbar \& Lause, 1992, pp. 418-426). However, to suit the taste of different generations of readers and viewers, the detective genre transformed itself into the police procedural subgenre not only by introducing a new type of detective and a new technique of detection, but also by changing its plot and motifs and by presenting new types of crime, settings, and props.

Discussing how the elements of the detective genre's textual convention have changed to produce the police procedural as the new variant of the detective genre is also to show how the police procedural subgenre is 
distinct from, and yet the same as the "parent" genre. To complete the discussion, it is necessary as well to compare how the police procedural is different from, and yet similar to the other subgenres of the detective genrethe Classical, "Golden Age," and the "hard-boiled"-in changing the elements of the "parent" genre.

To begin with, like other traditions in detective fiction, the police procedural also revolves around a mysterious occurrence which of course involves some kind of criminal action. Thus, the plotline of the police procedural generally follows its "parent" genre's which comprises of the three basic stages of death-detectionexplanation (Horsley, 2005, p. 12). Unlike the classic detective story that relies on ratiocination and the "hardboiled" tradition that uses the pursuit and infiltration, the police procedural uses the police routines as the method of resolution in its plot development (Dove, 1982, p. 49). Harriss went further by identifying the stages of the police procedural structure in more detail. In agreement with Bordwell's identification of detective films, Harriss (2008) also identified that the structure of television police procedural drama series typically contains two distinct segments: the crime and the investigation (p. 43).

The crime segment, according to Harriss (2008), is divided into the commission of the crime, in which a victim is involved in some mysterious occurrence, and the discovery of the crime, in which the victim is discovered. The investigation segment is divided into the beginning of the investigation, the phases of the investigation, the elucidation of the case and the identification of the perpetrator, the consequences of the identification, and finally the resolution (p. 46).

Harriss (2008) further explained the segments in detail. At the beginning of the investigation, the investigators are made aware of the case and are provided with background information and they relocate and begin investigating. The next is the six phases of the investigation which include 1) the investigators discover partial answers or snares by physically searching and/or questioning the informers/misinformers/experts, 2) the informers/misinformers/experts provide partial answers and/or snares, 3) the investigators/experts reveal/recount the discovery of the partial answers or snares, 4) the investigators identify a perpetrator/false perpetrator, 5) the investigators apprehend and question the perpetrator/ false perpetrator, and 6) the perpetrator/false perpetrator provides partial answers and snares. The phases of the investigation are then followed by the elucidation of the case and the identification of the perpetrator, in which the investigators elucidate the case; identifying the perpetrator as true or false. In this case, if the accused is determined to have been falsely accused, then the case is not fully elucidated and the narrative typically returns to the phases of the investigation. The consequences of the identification, in which the perpetrator is removed from the society, come after the elucidation of the case and the identification of the perpetrator. Finally, in the resolution, the investigators assess the case (p. 46).

Next, the kind of detective becomes the aspect that transforms the detective genre into the police procedural subgenre. It has been briefly mentioned in the introduction that unlike in the other traditions, the mysterious crime in the police procedural is investigated by the policemen/ policewomen who are assigned as detectives or the police detectives. Therefore, even if there are police in the story, it cannot be called a police procedural if they are not detectives, and thus do not solve mysteries (Dove, 1982, p. 2). Also, it cannot be called a police procedural if the fact that they are police has no effect on their characterization, or in other words, if they act like any other amateur or private detective who has no attachment to bureaucracy and law in solving crimes (Panek, 2003, p. 155).

At this point, it is worth mentioning that Dove (1982) used pronouns "he" and "she" in his explanation about the police procedural. This choice of pronoun shows that Dove (1982) is aware that in its development, the detective genre and its subgenres have accommodated more and more female detectives. The detectives of the Classical, "Golden Age," and "hard-boiled" traditions are exclusively, or almost exclusively, male. Even, all "hard-boiled" detectives are male (Van Dover, 2005, p. 13). The tendency to accommodate more female characters taking the leading role in detective story was started roughly in the mid-1970s when the rhetoric of the women's movement became a part of social discourses about women and equality (Mizejewski, 2004, p. 62).

Another distinct point relates to the technique of detection. It has also been briefly mentioned in the above that the term "procedural" refers to the new technique of investigation in which the police detectives follow specific departmental procedures in finding a solution to the mysterious crime. According to Dove (1982), whereas the Classical amateur detectives rely on ratiocination and scientific explanation and the "hardboiled" private investigators on canniness and agility, the police detectives follow certain police routines, such as using informants, stalking suspects, and making use of crime laboratory and forensics in their investigation activities. This point suggests that the police detectives in the police procedurals almost always detect or investigate crimes in team, and thus the responsibilities, the dangers, and eventually the credit are equally shared 
among the members of the team. Even if for the sake of popularity there is a main-character detective in the police procedural, he or she never works out the resolution of the mysterious crime with his or her lone brilliance. Instead, he or she is indebted to the collaborative works of other police for the resolution (p. 2).

It is necessary to note that Harriss (2008) emphasized the aspect of mystery and the term "procedural" in his definition. It makes his definition broader that he included not only police detectives, but also forensic scientists as "characters who actively investigate the mystery for the viewer" (p. 43). Forensic scientists more often than not work for a particular police department and do their job as part of a team effort of a group of police detectives to solve a mysterious crime. Therefore, forensic scientists are also bound to follow certain departmental procedures in doing their job. This is likely what makes Harriss consider them qualified to be included in his definition of the procedural. On top of that, Harriss apparently needed to use the broad definition to conveniently support his purpose of proving that Vladimir Propp's formalist method is still useful in genre studies.

The setting also marks the transformation of the detective genre into the police procedural. Unlike the Classical detective stories, for example, the police procedural makes use of open, urban settings. Panek (2003) noted that American police fiction in its early years frequently takes two major cities in the United States, New York and Los Angeles, as its setting. By the mid1990s, the two major cities were soon followed by other major cities, such as Denver, Indianapolis, Minneapolis, Detroit, Dallas, and Seattle. However, although there are some other major cities, such as Las Vegas, Miami, Baltimore, Detroit, Chicago, and Kentucky as well, New York and Los Angeles remain the most frequently used backdrops of American television police drama series (p. 159). In fact, according to Arntfield (2013), the New York Police Department (NYPD) and Los Angeles Police Department (LAPD.), as well as San Francisco Police Department (SFPD) and to a lesser extent, the Detroit Police Department (DPD), have emerged as departments of record within the American police-media system (pp. 389-390). Arntfield (2013) broadly defined the policemedia system as "a nationalist partnership that, using closely regulated and thus formulaic media like network television, fuses public and private interests that are mutually benefited by the myths generated through police stories" (p. 391).

In minor cases, variation occurs as the setting of police fiction is moved outside the American cities, for examples Tony Hillerman's Native American reservations in the southwest and Sue Henry's Alaska (Panek, 2003, p. 159). Likewise, the setting of television police drama series is also moved outside the American cities, for example, to states highways in Highway Patrol (Syndicated, 1955-1959) and CHIPs (NBC, 1977-83) and the islands of Hawaii in Hawaii Five-O (CBS, 1968-80).

In relation to the use of the open, urban setting, in particular, the police procedural uses the setting of a police precinct. Like its open, urban setting, the police procedural's setting of the police precinct also changes. Panek (2003) pointed out that in the new American police novel, the setting of a police precinct has covered the more specialized police departments, not only homicide, but also K-9 unit, bomb squad, medical examiner's office, and internal affairs. Similarly, television police drama series also includes the more specialized police departments, from homicide to robbery/burglary, public morals (prostitution and gambling), narcotics, internal affairs, crime laboratory, the K-9 unit, bomb squad, SWAT team, and patrol (p. 159).

Concerning theme, although its detectives rely more on team work instead of individual bravery, strength, and resourcefulness like its Classical, "Golden Age," and "hard-boiled" counterparts, the police procedural is still a conservative ritual of assurance (Mittell, 2004, p. 15). It still delivers "mediation-redemption and utopia-aspromise" themes (Schatz, 1981, p. 35). The detective hero also mediate the cultural contradictions inherent within his/her milieu and redeem his/her milieu from an individual violation of the social order that embodies a collective and unchanging ideal belief and value (Schatz, 1981, p. 34; Bertens \& D'haen, 2001, p. 2; Roman, 2005 , p. 41). However, as previously stated, they do it by solving mysterious crimes in teams and equally share the responsibilities, the dangers, and eventually the credit among the members of the team. Although there is a main-character detective in the police procedural, he or she never solves the mysterious crimes with his or her lone brilliance, instinct, toughness, or perseverance like his or her Classical, "Golden Age," and "hard-boiled" counterparts, but by collaboratively working with other police detectives for a resolution (Dove, 1982, p. 2).

As explained before, the detective genre accommodates the need to shift the responsibility to fight crimes from private detectives to the right persons with visible authority - the police detectives. The visibility of the authority is retained by the use of badge and revolver. The badge and revolver represent the law that both civilian, as well as non-civilians, must obey. Wearing the badge and revolver has ensured that the police detective is seen as an agent of law, who must be 
obeyed by any person subject to the law. Disobeying, or even just refusing to cooperate with, the police detective can be considered as obstructing the law, and the police detective has every right to apprehend the disobeying subject. Therefore, it can be said that the badge and revolver are the iconic props of the police procedural. In some instances, police uniform can also be an iconic prop of the police procedural. The badge and revolver, however, are more likely to acquire emotional meaning because the police detectives rarely wear police uniform in fulfilling their day-to-day duty.

The increasing reliance on investigative technology has made it another iconic prop of the contemporary police procedural. The use of a police crime laboratory, for example, is not unique to the police procedural. The other traditions of the detective story involve analysis and reports on bloodstains, fingerprints, and footprints, on different levels of depth and importance, but the increasingly sophisticated investigative technology available to police officers plays a much more critical role in the police procedural (Dove, 1982, p. 61; Gates, 2006, pp. 162-163; Moody, 2003, pp. 237-238). The prominent American television police procedural drama series CSI: Crime Scene Investigation (CBS, 2000-2015) and its spin-offs, for example, focus on representing the increasing reliance on science and technology to track, identify, and stop murderers to the extent that the detective heroes can only provide " "court positive', $[\ldots]$ a case that will stand up before a jury, every step of the way, under cross examination, free of the single flaw that could wipe out [all] the gain" (Dove, 1982, p. 51) by the use of highly sophisticated crime lab and meticulous computer databases. The representation of the increasing reliance on science and technology in CSI and its spin-offs has created a phenomenon known as the "CSI effect" that may be influencing juries in real-life court cases (Lavigne, 2009, p. 384). In its recent development, it becomes more and more common to watch the increasing reliance on science and technology in many American television police procedural drama series.

It has been explained earlier that since the police procedural has a known counterpart in real life, it is then crucial for the subgenre to rely on the aspects of authenticity and reality (Dove, 1982, p. 3; Roman, 2005, p. 41; Mittell, 2004, p. 126). Therefore, it is logical to emphasize the authentic and realistic aspects in a definition of the police procedural like Arntfield's (2011) definition in the following.

By invoking the style of documentary film, the police procedural, as the name suggests, favours the accurate portrayal of existing and established police procedures over the melodrama of other ancillary crime genres. It also endeavours to accurately and earnestly reflect the political economy, policies, hierarchies, occupational subcultures, and decorum of actual — and typically American-law-enforcement agencies, whether for better or worse (p. 76).

Being called "a discourse of the real" by Langford (2005), documentary principally "relies on, and is judged by, an explicit profession of encountering reality and being led by it, rather than shaping reality into generically harmonious forms, [...]" (p. 258). One of the norms and conventions that comes into play for a documentary is a reliance on social actors, or people in their everyday roles and activities, as the central characters (Nichols, 2001, p. 26). Thus, invoking the style of a documentary film means invoking authentic representation to create an as realistic as possible portrayal of the police detective and the workings of a police department in real life. Authenticity is usually achieved through the use of access to a certain police department's case files provided by a technical advisor who is a real police detective of a certain police department (Mittell, 2004, p. 128).

Once it established itself as a subgenre, the police procedural has developed its own textual conventionthe formal attributes and patterns of meaning - that become part of the formula that is generally employed by writers and have come to be expected by readers or viewers (Dove, 1982, p. 112). This part mainly discusses Dove's (1982) explanation of the textual convention of the police procedural. Because his book is dedicated to especially discuss the police procedural subgenre, Dove (1982) was able to identify the textual convention of the police procedural and provided a thorough explanation of the convention.

According to Dove (1982), there are a number of accepted conventions of the police procedural, and if these conventions are considered as limitations and handicaps, they are basically aimed at contributing to the realistic atmosphere and tone of the police procedural stories (p. 113). The first convention relates to the personal life of the police detectives and the other five concerns with the nature of the police works that are considered frustrating and unrewarding and are surrounded by coincidence and shadowed by the probability of failure. Although exception occurs, it is conventionally accepted that the police detective is a married man or woman who may be relatively happy, but still needs to worry about family problems like a discontented spouse, a tight family 
budget, or rebellious children (Dove, 1982, p. 112). The other five conventions that are stated in terms of limitations and handicaps are the "Ordinary Mortal," the "Thankless Profession," the "Tight Enclave," the "Fickle Breaks," and the "Tyranny of Time" (Dove, 1982, p. 113).

In relation to the first convention, at present, it is more likely to suggest that it has developed to become an exception for a police detective protagonist to be represented as a relatively happy married man or woman who still needs to worry about family problems, especially on American television. It has become more rare to watch a television representation such as D.B. Russell of the CSI: Crime Scene Investigation (CBS, 2000-2015) who is a sharp forensic expert and also a relatively happy family man with everyday family problems or like Roger Murtaugh of the Lethal Weapon (Fox, 2016-present) who is a happy married detective with usual family problems. It is more common to watch the police detective, both male and female, being represented as a man or woman with a troubled love relationship or marriage, a divorced man or woman, or a single parent on American television.

In the "Ordinary Mortal" convention, in contrast to the gifted classic detective, the police detective appears to be a commonplace individual who has a commonplace ability, lacks both intellectual brilliance and cultural background, and is incapable of heroic action. The police detective is good at doing his job, but he/she more often than not is not really educated and generally lacking in cultural finesse. Heroes are believed to be difficult to find in a police force. However, for the sake of narrative interest, this particular police detective in this particular story needs to be represented as exciting, superior, gifted, and once in a while heroic by the writers (Dove, 1982, pp. 114-117).

The convention of the police detective as a commonplace individual who has a commonplace ability and lacks both intellectual brilliance and cultural background is made possible by their workingclass status. It is the status that is often explored to emphasize vulnerability and marginality, especially in the representation of female police detectives (see Mizejewski, 1993; Tasker, 1998). In American society, getting a proper education is always an issue for working class people. Therefore, it becomes realistic and authentic to represent the police detectives as not really educated and generally lacking in cultural finesse. Of course, exceptions are always likely to happen, for example on American television, there is the genius three $\mathrm{PhD}$ holder in Mathematics, Chemistry, and Engineering and an autodidact Dr. Spencer "Spence" Reid and the high intelligent Dr. Tara Lewis of Criminal Minds (CBS, 2005-present) and the genius chief medical examiner Dr. Maura Isles of the Rizzoli and Isles (TNT, 2010-2016).

As for the convention of the "Thankless Profession," it is expected that a police detective shares the same idea with his/her fellow police detectives, but never with outsiders, that police work is unrewarding and frustrating. This idea is usually intensified by exasperation with the difficulties the police detectives encounter on a daily basis - lack of appreciation shown by their low pay, the public's hostile and rude or indifferent attitudes toward them, and the senseless regulations that hamper them instead of making their job easier. The fact that it is crucial to keep the idea that the police work is unrewarding and frustrating from outsiders is related to the next convention - the "Tight Enclave" (Dove, 1982, p. 119).

The "Tight Enclave" convention prescribes that the police community is a community "whose members cover each other's derelictions and infractions, who take a superior, exclusive attitude toward the non-police community, and who are ready to avenge at all costs any threat of violence to their fellow officers" (Dove, 1982, p. 121). Facing danger together on a daily basis generates strong solidarity of the "Tight Enclave" to ensure security is gained. The strong solidarity is built within the system of favors - when there is a minor violation of the rules or dereliction of duty, it is routine for officers of the same rank to cover for each other and for superiors to cover for subordinates. Therefore, when a fellow policeman commits or is under suspicion of committing a crime, it becomes the test of the solidarity of the "Enclave." However, the ultimate test is when a fellow policeman is murdered. Being a closed society, civilians remain excluded from the police force and admissions of weakness and shortcomings in the department are not permitted outside the society (Dove, 1982, pp. 122-123). This is what makes it consensual to never share the idea that policing is a thankless profession with outsiders.

The "Tight Enclave" is an important convention because it highlights one of the important differences between the various traditions of the detective genrethe type of detective. The detectives of the traditional formal-problem story and the private investigator of the "hard-boiled" story are essentially individualists, but the detective of the police procedural is a member of a fellowship that is always ready to provide backups anytime he/she is in danger, covers for him/her when he/she is in trouble with the public and the department, and hunt and convict his/her murderer if he/she is killed (Dove, 1982, p. 125).

In relation to the "Fickle Breaks" convention, 
unlike the classic detective and the "hard-boiled" detective story, the police procedural story gives room to the occurrence of the fickle breaks or the unpredictable and the unexpected happenings that can change the course of the investigation (Dove, 1982, p. 126). In dealing with the fickle breaks, the police detectives can only rely on their own commitment to giving attention to detail and to pursuing every promising lead. Nevertheless, they will never find any certainty in their work. Sometimes, the breaks go bad. It may be because of pure bad luck, but mostly it is because of the loss of valuable clues in the unmanageable flood of available information or the failure to communicate something vital to the people working on the case for not recognizing its significance. Sometimes, the breaks take the police detectives' sides so they get lucky. The good breaks may come from sheer luck, but often it comes from the tendency of the criminal to make mistakes. An important point to note about this convention is that actually no major case in the procedurals is solved by pure luck, though bad breaks delay the solution to some. For the writers of the police procedural, leaving too much to chance or coincidence is just like betraying the traditions of mystery fiction (Dove, 1982, pp. 125-127).

The last convention, the "Tyranny of Time," is mostly applied in police procedural fiction. Unlike the other traditions of detective genre, the authors of the police procedural take the assumption that time never takes the police detectives' sides, to the extent that if they are unable to solve a case quickly - conventionally, more or less within forty-eight hours, it is unlikely they can solve it at all (Dove, 1982, p. 128). Nevertheless, narrative necessity often takes precedence over the timeconvention. For the sake of narrative necessity, one month can sometimes be the average time to solve a crime case (Dove, 1982, p. 130).

In contrast to amateur detectives, the real life police detectives do not get the advantage of having the privilege of solving one case at one time. As a consequence, reflecting real-life police work, the police procedural authors routinely burden their police detectives with truly heavy caseload that the police will never have enough time for anything (Dove, 1982, pp. 128-129). The circumstances that usually make time tyrannical are the pressure of overworking, political pressure, and of course, certain types of crime-usually life-threatening types like baby or child kidnapping or terrorist bomb threats. The pressures may come from inside or outside the department. From the inside, the pressure is usually applied by superiors. From the outside, the pressures can be from a hostile public or an outsider with a certain personal interest as well as advanced technology and mobility available to criminals (Dove, 1982, pp. 129130).

By attaining its own textual convention, the police procedural has flourished to become an established subgenre of the detective genre, and at present, American television has become the right medium to see how the police procedural has helped the detective genre maintain its popularity. Entering the new millennium, the popular detective drama series on American television were in the form of the police procedural and many of them have become long-running series that have spin-offs that are as successful as the original series, such as Law \& Order (NBC, 1990-2010) and its spin-offs Law \& Order: Special Victims Unit (NBC, 1999-present) and Law \& Order: Criminal Intent (NBC, 2001-2011); CSI (CBS, 2000-2015) and its spin-offs CSI: Miami (CBS, 20022012), CSI: NY(CBS, 2004-2013), and CSI: Cyber (CBS, 2015-2016); NCIS (CBS, 2003-present) and its spin-offs NCIS: Los Angeles (CBS, 2009-present) and NCIS: New Orleans (CBS, 2014-present); Criminal Minds (CBS, 2005-present) and its spin-offs Criminal Minds: Suspect Behavior (CBS, 2011) and Criminal Minds: Beyond Borders (CBS, 2016-2017); and The Closer (TNT, 20052012) and its spin-off Major Crimes (TNT, 2012-2018). There were also other series, such as Crossing Jordan (NBC, 2001-2007), Cold Case (CBS, 2003-2010), Karen Sisco (ABC, 2003-2004), NYPD Blue (ABC, 1993-2005), Bones (Fox, 2005-2017), Castle (ABC, 2009-2016), Rizzoli and Isles (TNT, 2010-2016), Unforgettable (CBS, 2011-2016), and etc.

\section{CONCLUSION}

It can be concluded that experts have apparently provided a working definition of the police procedural after having identified the interplay between the familiar and the twists of the familiar-how the new variant is different from, and yet remains the same as the "parent" genre. While the third definition puts emphasis on the authentic and realistic aspects of the police procedural, the first two definitions can be used as a reference to elaborately discuss the police procedural as a variant or subgenre of the detective genre. The police procedural retains the basic conventional elements of the detective genre-plot and motifs, character, setting, theme, and props, but it twists these elements and turns them into invention to keep the interest of the readers and viewers. Having established itself as a subgenre, the police procedural grows to become formulaic by creating its own textual convention. It is a formula that is generally employed 
by writers and has come to be expected by readers or viewers. By doing so, the police procedural has helped the detective genre as its "parents" genre stay popular.

\section{REFERENCES}

Arntfield, M. (2011). TVPD: The generational diegetics of the police procedural on American television. Canadian Review of American Studies, 41(1), 7595. doi:10.1353/crv.2011.0003

Arntfield, M. (2013). Out of exile: The recusal of the Chicago Police from American film and television, 1961-2011. Canadian Review of American Studies, 43(3), 388-410. Retrieved from http://muse.jhu.edu/ journals/crv/summary/v043/43.3.arntfield.html

Bell, I. A. (2003). Eighteenth-century crime writing. In Cambridge companion to crime fiction (pp. 7-18). Cambridge: Cambridge University Press.

Bertens, H., \& D'haen, T. (2001). Introduction. In Contemporary American crime fiction (pp. 1-16). New York: Palgrave.

Dove, G. N. (1982). The police procedural. Bowling Green: Bowling Green State University Popular Press.

Gates, P. (2006). Investigating national heroes: British sleuths and American dicks. In Detecting men: Masculinity and the Hollywood detective film (pp. 55-94). Albany: State University of New York Press.

Gates, P. (2006). Investigating the hero: The criminalist. In Detecting men: Masculinity and the Hollywood detective film (SUNY series, cultural studies in cinema) (pp. 157-188). Albany: State University of New York Press.

Harriss, C. (2008). Policing Propp: Toward a textualist definition of the procedural drama. Journal of Film and Video, 60(1), 43-59. doi:10.1353/jfv.2008.0001

Horsley, L. (2005). Introduction. In Twentieth-century crime fiction (pp. 1-11). Oxford, England: Oxford University Press.

Langford, B. (2005). Genre: Breaking the frame. In Film benre: Hollywood and beyond (pp. 257-272). Edinburgh: Edinburgh University Press.

Lavigne, C. (2009). Death wore black chiffon: Sex and gender in CSI. Canadian Review of American Studies, 39(4), 383-398. doi:10.1353/crv.0.0047

Mittell, J. (2004). Television genres as cultural categories. In Genre and television: From cop shows to cartoons in American culture (pp. 1-28). New York: Routledge.

Mittell, J. (2004). Before the scandals - Genre historiography and the cultural history of the quiz show. In Genre and television: From cop shows to cartoons in American culture (pp. 29-55). New York: Routledge.

Mittell, J. (2005). Policing genres - Dragnet's texts and generic contexts. In Genre and television: From cop shows to cartoons in American culture (pp. 121-152). New York: Routledge.

Mizejewski, L. (1993). Picturing the female dick: The Silence of the Lambs and Blue Steel. Journal of Film and Video, 45(2/3), 6-23. Retrieved from http://www. jstor.org/stable/20688003

Mizejewski, L. (2004). Jiggle, camp, and couples: Investigating couples. In Hardboiled \& high heeled: The woman detective in popular culture (pp. 62-77). New York: Routledge.

Moody, N. (2003). Crime in film and on TV. In Cambridge companion to crime fiction (pp. 227-243). Cambridge: Cambridge University Press.

Nachbar, J., \& Lause, K. (1992). Introduction would you repeat that--please!: The meaningful delight of formula in the popular arts. In Popular culture: An introductory text (pp. 414-429). Bowling Green: Bowling Green State University Popular Press.

Nichols, B. (2001). How do documentaries differ from other types of film? In Introduction to documentary (pp. 20-41). Bloomington: Indiana University Press.

Panek, L. L. (2003). Post-war American police fiction. In Cambridge companion to crime fiction (pp. 155-170). Cambridge: Cambridge University Press.

Priestman, M. (2003). Introduction: crime fiction and detective fiction. In Cambridge companion to crime fiction (pp. 1-6). Cambridge: Cambridge University Press.

Roman, J. (2005). Tinseltown comes to TV. In From daytime to primetime: The history of American television programs (pp. 11-21). Westport, CT: Greenwood Press.

Schatz, T. (1981). Film genres and the genre film. In Hollywood genres: Formulas, filmmaking, and the studio system (1st ed., pp. 15-36). New York: Random House.

Tasker, Y. (1998). Investigating women: Work, criminality and sexuality. In Working girls: Gender and sexuality in popular cinema [Adobe eReader Format] (pp. 91113).

Van Dover, J. K. (2005). Preface. In We must have certainty: Four essays on the detective story (pp. 9-15). Selinsgrove, PA: Susquehanna Univ. Press. 